\title{
DIGITAL DESIGN AND IMPLEMENTATION OF SOYBEAN GROWTH PROCESS BASED ON L-SYSTEM
}

\author{
Hongmin Sun ${ }^{1, *}$, Leqiang $\mathrm{Ai}^{1}$, Xinzhong Tang ${ }^{1}$ \\ 1Department of computing, Engineering College, Northeast Agricultural University, Harbin \\ 150030, China \\ * Corresponding author, Address: Department of Computer Science and Technology, \\ Engineer College, Northeast Agriculture University, Harbin, China, 150030, Tel: +86-0451- \\ 55191749, Fax: +86-0451-55190170, Email: sunhongmin111@126.com
}

Abstract: Aiming at the Present Condition of Research on soybean growth model, in order to recur the overall dynamic process of soybean growth, we parameterized the main factors that can affect the plants' physical development and built the soybean plant growth model by adopting the classical biologic plant growth logistic equation and the Self-similarity of plant morphology. In VC6.0 environment, we applied OpenGL technology and L-system to simulate the soybean plant type topological structure and the plant leaves in computer to simulate the whole process of soybean plant type growth more factually which creates advantaged conditions to research on high yield soybean plant shape.

Keywords: Virtual soybean, growth model, topological structure, L-system

\section{INTRODUCTION}

Virtual plant is a simulation to growth and development status of plant in 3D space which is based on a large number of data of individual plant. It can create plant with three-dimensional effects and visualizing function, also obtain the common results of plant physiological ecology processes and morphological structure process.

Soybean is the one of the world's major food crops, the study on virtual soybeans mainly focus on two research direction, one direction focus on the simulation of plant structure, the other focus on the simulation of physiology

Sun, H., Ai, L. and Tang, X., 2008, in IFIP International Federation for Information Processing, Volume 259; Computer and Computing Technologies in Agriculture, Vol. 2; Daoliang Li; (Boston: Springer), pp. 791-797. 
function recently, the next hot research will be the simulation of commoneffect that integrated the two factors above (Zheng et al., 2006). Soybean physiological function can influence the form of soybeans; the other way round, soybean pattern of soybean can also affect the efficiency and process of physiological function. By controlling the environment factors that can affect the soybean growth to simulate the form of soybean, then according to the simulation of soybean production patterns to determine efficiency of the soybean biological function (such as photosynthesis efficiency), finally selecting the high-yielding soybean plant type and transforming soybean plant type through the biological genetic engineering. This research can make important impact to increase soybean yield and have great practical significance (He et al., 2004).

L-system simulation to herbs can easily be understood and realized (Jin et al., 2002), so the obvious and practical approach of virtual plant is to model by using L-system and OpenGL technology with combining the plant growth equation in the VC++ MFC framework, digital designing and implementing the simulation of soybean growth process.

\section{MATIERIALS AND METHOD}

\subsection{Geography and Meteorology}

Variety selection: DongNong45. Main stem type, limited growth, round leaf, early maturing, The period of growth was about 87 days.

Planting place: The virtual plant laboratory of northeast agricultural university, the Average light were 8.6 hour, The temperature in laboratory $18^{\circ} \mathrm{C}-25^{\circ} \mathrm{C}$, humidity $30 \%-70 \%$.

Measurement tool: $15-\mathrm{cm}$ ruler (precision $1 \mathrm{~mm}$ ) and spiral micrometer (precision $0.01 \mathrm{~mm}$ ), electronic balance, CI-203 laser leaf area meter, vernier caliper.

Shoot tool: Canon Power Shot S45.

\subsection{Data Collection}

Observation period: From November 23, 2005 to February 10, 2006 (sowing in November 17, 2005)

Experiment content: In this experiment, we select four representative soybean plant, measure and record a individual soybean plant at the same time every two days. The measurement results include the internode distance, internode thickness, the length and thickness of petiole and little 
petiole, the length and width of every leaf, leaf weight, petiole weight, internode weight etc, 1745 Data were presented. We also take photography for the individual soybean plant when it's measured.

Table1 shows the partial data:

Table 1. Soybean growth process parameters

\begin{tabular}{l|ccc|ccc|ccc}
\hline \multirow{2}{*}{ Week } & \multicolumn{3}{|c|}{ Internode } & \multicolumn{3}{c|}{ Petiole } & \multicolumn{3}{c}{ Leaf area $\left(\mathrm{cm}^{2}\right) /$ fresh weight $(\mathrm{g})$} \\
\cline { 2 - 9 } & $\begin{array}{c}\text { Cross } \\
\text { sectional } \\
\text { diameter } \\
(\mathrm{mm})\end{array}$ & $\begin{array}{c}\text { Length } \\
(\mathrm{cm})\end{array}$ & $\begin{array}{c}\text { Fresh } \\
\text { weight } \\
(\mathrm{g})\end{array}$ & $\begin{array}{c}\text { Cross } \\
\text { sectional } \\
\text { diameter } \\
(\mathrm{mm})\end{array}$ & $\begin{array}{c}\text { Length } \\
(\mathrm{cm})\end{array}$ & $\begin{array}{c}\text { Fresh } \\
\text { weight } \\
(\mathrm{g})\end{array}$ & Leaf 1 & Leaf 2 & Leaf 3 \\
\hline 1 & 1.60 & 0.90 & 0.04 & 1.36 & 0.40 & 0.02 & $-/ 0.06$ & $-/ 0.06$ & $-/ 0.06$ \\
2 & 2.40 & 1.55 & 0.10 & 1.88 & 3.20 & 0.11 & $8.364 / 0.12$ & $10.679 / 0.14$ & $8.116 / 0.15$ \\
3 & 3.12 & 1.90 & 0.44 & 1.36 & 6.20 & 0.24 & $6.890 / 0.09$ & $5.257 / 0.13$ & $9.490 / 0.17$ \\
4 & 3.70 & 3.4 & 0.37 & 1.58 & 10.3 & 0.27 & $14.915 / 0.28$ & $16.711 / 0.30$ & $13.179 / 0.23$ \\
5 & 4.72 & 2.30 & 0.38 & 2.06 & 9.40 & 0.22 & $9.577 / 0.13$ & $13.394 / 0.18$ & $11.865 / 0.14$ \\
\hline
\end{tabular}

\section{RESULTS AND ANALYSIS}

\subsection{Soybean Topological Structure L System Design}

Soybean topological structure has certain characteristics, For example: Relatively simple structure, Hierarchy, Self-similarity etc, so we use symbol instead of each organ which makes it is easy to design L-System, Ultimate design of the L-system are as follows:

//Iteration Times

Iteration $=\mathrm{N}$

//According to observation, set space rotation angle

Angle $=45$

//the initial Character Set

$\mathrm{V}=\{\mathrm{I}, \mathrm{i}, \mathrm{Pl}, \mathrm{Pr}, \mathrm{P}, \mathrm{p}, \mathrm{A}, \mathrm{L}, 1, \mathrm{z},[],,+,-, \&, \wedge, \backslash, /, \mid\}$

The initial expression: // Soybean topological structure which only has cotyledon

$\omega: \mathrm{I}[+\mathrm{z}][-\mathrm{z}] \mathrm{A}$

$/ /$ production expression

$(\mathrm{N}=1)$ //Structural Iterative Expression of the soybean univalent period

P1: $A \rightarrow I[+i L][-i L] A$

$(\mathrm{N}>1)$ //Structural Iterative Expression in different growth periods 
$\mathrm{N}$ is odd $\mathrm{P} 2: \mathrm{A} \rightarrow \mathrm{I}[+\mathrm{Pl}] \mathrm{A}$

$\mathrm{N}$ is even $\mathrm{P} 3: \mathrm{A} \rightarrow \mathrm{I}[-\mathrm{Pr}] \mathrm{A}$

//The final iteration expression

//Description of the petiole and trifoliate leaf

$\mathrm{Pl} \rightarrow \mathrm{p}[\mathrm{iL}][/ \mathrm{iL}][-\mathrm{iL}]$

$\mathrm{Pr} \rightarrow \mathrm{p}[\mathrm{liL}][/ \mathrm{iL}][+\mathrm{iL}]$

Various symbols which represent the meaning indicated in the following table 2.

Table 2. Soybean framework represented by some symbols

\begin{tabular}{llcl}
\hline Symbol & Meanings & Symbol & Meanings \\
\hline I & Internode & $\mathrm{i}$ & Cotyledon, compound leaf ramastrum \\
$\mathrm{Pl}$ & Left branching & $\mathrm{Pr}$ & Right branching \\
$\mathrm{P}$ & Compound leaf part & $\mathrm{p}$ & Compound leaf petiole \\
$\mathrm{z}$ & Cotyledon & $\mathrm{L}$ & Compound leaf \\
$\mathrm{l}$ & Univalent & $\mathrm{A}$ & Apical meristem \\
Iteration & Iteration Times & Angle & The included angle of main stem and ramificate \\
\multicolumn{1}{c}{,],+,-, \&, \wedge, \perp, /}$, & & The meaning of L-system \\
\hline
\end{tabular}

\subsection{Construction of Soybean Growth Equation}

During the process of the experiment, integrant data of the soybean previous growth was recorded due to the environmental restriction of measurement. The measuring cycle is two days, and the function trend reflected from the data can be shown in table 3 .

Table 3. Data of internodes length from 1st to 13th days

\begin{tabular}{lccccccc}
\hline Day N & 1 & 3 & 5 & 7 & 9 & 11 & 13 \\
\hline Internodes length/mm & 9.0 & 11.20 & 13.30 & 15.50 & 16.70 & 18.10 & 19.0 \\
\hline
\end{tabular}

These data roughly show the growth process of internodes length. If these data is directly adopted to construct a growth equation, the accuracy of it will be greatly discounted. To make up its inexact resulting from the inadequacy of data, we adopt a method of data combination. Here six degree polynomial is used to describe these data. Constructing a .mmf file through $1 \mathrm{stOpt}$ software to answer, so as to get interpolation polynomial as followed:

$$
y=-0.0017 x^{6}+0.073 x^{5}-1.215 x^{4}+9.769 x^{3}-39.14 x^{2}+77.08 x-35.479
$$


Then a number of interpolation data are estimated from this interpolation polynomial as showed in table 4 .

Plant growth follows the classical logistic equation, therefore making use of the mathematical software-1stopt to construct .mmf program to fitting logistic equation by using interpolation data, at last confirming the growth equation parameter of each organ of the individual soybean plant. We can get the result as follow:

$$
\begin{aligned}
& \mathrm{W}=54.336683977435 \\
& \mathrm{k}=6.40478984980516 \\
& \mathrm{n}=0.506995309056227
\end{aligned}
$$

Thus a more accurate curve equation of the soybean internodes length can be got as followed. $\mathrm{W}(\mathrm{t})$ indicates the length of certain growth time and $\mathrm{t}$ indicates the parameter of the growth time.

$$
W(t)=\frac{54.3367}{1+6.4 .48 e^{-0.5070 t}}
$$

Table 4. Data of internodes length after polynomial interpolation (mm)

\begin{tabular}{lccccccccccccc}
\hline Day N & 1 & 2 & 3 & 4 & 5 & 6 & 7 & 8 & 9 & 10 & 11 & 12 & 13 \\
\hline $\begin{array}{l}\text { Internodes length } \\
(\mathrm{mm})\end{array}$ & 9.0 & 10.10 & 11.20 & 12.00 & 13.30 & 14.42 & 15.50 & 16.20 & 16.70 & 17.46 & 18.10 & 18.70 & 19.0 \\
\hline
\end{tabular}

\subsection{Construction of the Main Organ Model}

The paper takes soybean leaf as the main object to discusses the construction method of the soybean organ model. By means of the computer image processing, L system is applied to realize the simulation of leaf configuration and texture. The setting of light source and leaf texture can lead to the visual model of it. The construction of the leaf visual model is in the same plane of the whole leaf. But in fact, the axis of the soybean leaf configuration is the main nerve and the left and right leaves shape a certain angle. Therefore the left and right leafs respectively need to be processed in terms of rotation and introduced parameter $\alpha$ to realize the control of rotation. $\alpha$ refers to the plane model of the leaf and the value range of the rotating angle is from 0 to 90 . (Kang et al., 2006)

The translation and rotation of the whole leaf also makes a parameter design. By means of regulating the translation and rotation parameter, the three-dimensional visual model of the leaf can show different angles and conditions. In imitating the duplicating leaf, the leaf moves the leaf handle along the axis Y. Fig. 1 simulates the duplicating leaf. 


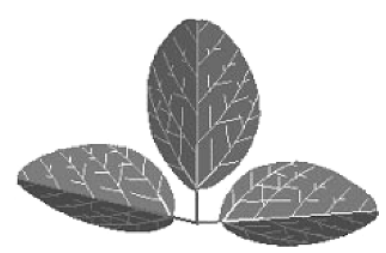

Fig. 1. Three-dimensional visual model of soybean leaves

The position processing method of a three-leaf leaf is that the leaf on the left and right moves the length of the leaf handle lt along the axis $\mathrm{Y}$ and then respectively rotates the corresponding the angle $\mathrm{z}$ along the axis $\mathrm{Z}$. The length of the leaf handle is larger than that of the leaf in the middle.

\subsection{The Realization of the Visual Model}

After confirming the topological structure and growth equation, we can apply the equation into the topological structure and simulate the soybean growth process in the three-dimensional environment by means of the integration development environment $\mathrm{VC}$ and 3D function library OpenGL (Song et al., 2003). In simulating the soybean growth process, the method is the technique of s mapping in OpenGL (Cai et al., 2002) and the final simulating effect is shown as Fig. 2.

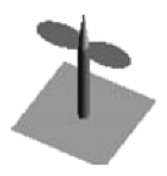

$\mathrm{t}=5$

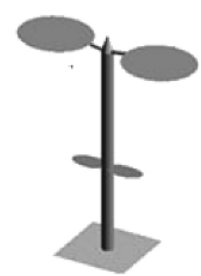

$\mathrm{t}=33$

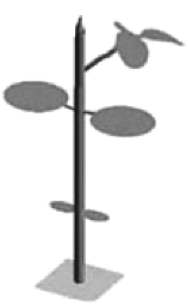

$\mathrm{t}=40$

Fig. 2. Simulation graphics of soybean growth

\section{CONCLUSION}

The paper combines L system and the plant growth model to realize the imitation of the soybean growth process. In terms of configuration and function, the effect of environment on the plant growth is fully revealed. However, the environment element involved in the model only refers to the time element and other environment elements closely related with the plant growth such as light, water and temperature need to be further perfected after collecting the experiment data to be used in the model. At the same time the 
real sense process of the soybean vein and leaf surface still need to be further researched into and dealt with.

\section{ACKNOWLEDGEMENTS}

This study has been funded by Natural Science Foundation of Heilongjiang province (Contract Number: C200607).It is also supported by Science and Technology Department of Heilongjiang province, China (Contract Number: GC04B712), and program for Innovative Research Team of Northeast Agricultural University, "IRTNEAU". we also thanks to the Northeast Agricultural University Virtual Agricultural Research Center for the experimental equipment and technical support.

\section{REFERENCES}

Zheng P, Su Z B, Kang L. Modeling of virtual soybean topology based on growth function. Journal of Agricultural Mechanization Research, 2006, 7:193-195.

He S W, Chang S H, Wu D L. Biological Characteristics of four different soybean varieties. Journal of Acta Pratacultural Science, 2004, 13:70-75.

Song Y H, Guo Y, Li B G, Philippe de Reffye. Virtual maize model I. biomass partitioning based on plant topological structure, Acta Ecologica Sinica, 2003, 23:23332341.

Cai Z J. The application of L-system in plant imitation and visualization on computer, Journal of Agricultural University of Hebei, 2003, 26: 98-101.

Jin R Z, Wang Z Y. Essential Concept of L-system and Examples. Journal of Tianjin Agricultural College, 2002, 9: 49-54.

[Kang L, Su Z B, Zheng P, Li Y F. Research on modeling leaf venation based on L-system Journal of agricultural mechanization research, 2006, 7:180-181. 